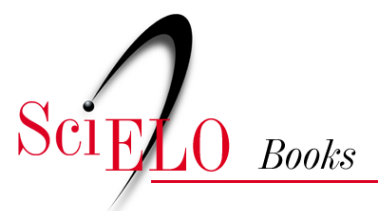

\title{
4. Buscando uma compreensão para os nervos das mulheres
}

\author{
Maria Lucia da Silveira
}

\section{SciELO Books / SciELO Livros / SciELO Libros}

SILVEIRA, M. L. Buscando uma compreensão para os nervos das mulheres. In: $O$ nervo cala, o nervo fala: a linguagem da doença [online]. Rio de Janeiro: Editora FIOCRUZ, 2000. Antropologia e saúde collection, pp. 83-94. ISBN: 978-85-7541-609-9. Available from: doi:

$10.7476 / 9788575416099.005$. Also available in ePUB from:

http://books.scielo.org/id/k4vp7/epub/silveira-9788575416099.epub.

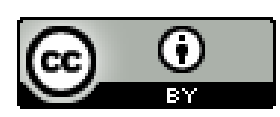

All the contents of this work, except where otherwise noted, is licensed under a Creative Commons Attribution $\underline{4.0 \text { International license. }}$

Todo o conteúdo deste trabalho, exceto quando houver ressalva, é publicado sob a licença Creative Commons Atribição 4.0.

Todo el contenido de esta obra, excepto donde se indique lo contrario, está bajo licencia de la licencia Creative Commons Reconocimento 4.0. 


\section{4}

\section{Buscando uma Compreensão para os Nervos das Mulheres}

\section{GÊNER0 E SAÚde}

Através dos séculos, uma poderosa ideologia foi construída para determinar a imagem da mulher e seu papel na vida social: conceitos de inferioridade, emotividade, falta de lógica e fragilidade, refletidos nas diversas instituições sociais, limitando o pleno desenvolvimento da capacidade feminina em igualdade de condições com os homens. Também desenvolveram-se as noções de saber e autoridade masculina, de posse do homem sobre o corpo e os atos da mulher. Até hoje o sistema aplica leis e usa mitos, alimenta costumes e usos, estabelece toda uma cultura para instrumentalizar a repressão à mulher. (grifos meus)

Prochmanm

Homens e mulheres, é inegável, diferenciam-se biologicamente; porém, suas diferenças recebem amplo reforço e suas similaridades esmaecem-se sob a ótica cultural, em especial nas sociedades machistas como a nossa (cf. Wallen, 1979; Costa, 1983b, entre outros).

Numa obra dirigida ao público feminino, Witkin-Lanoil (1985b) mostra que a biologia feminina expõe a mulher, diferentemente do homem, a ciclos, hormônios e funções que a tornam mais vulnerável a muitos agravos: o homem não menstrua, não engravida, não pare, não tem útero caído ou cistocele, não sofre com os calorões ou passa por mudanças tão dramáticas quanto as da menopausa, não amamenta, não tem TPM... Por não maternar, o homem não sofre alguns constrangimentos culturais, como ter de provar seu estado civil, a ausência de gravidez, a virgindade...

Porque a cultura valoriza, a mulher precisará ser feminina e atraente, porém, jamais oferecida; terá de ajudar na economia doméstica com seu salário, mas sem descuidar jamais de ser boa dona de casa, mãe carinhosa e, sobretudo, uma boa mulher para seu homem. É bom que ela seja afirmativa mas nunca agressiva, que seja responsável mas mantenha um espírito pueril para deleite dos homens... 
E, em geral, cabem ainda à mulher algumas tarefas extras ligadas também ao ciclo da vida: cuidar dos velhos e das crianças, dos deficientes físicos e mentais, ser professora de pré-escola e das classes de alfabetização, compor a maioria da mão-de-obra nos hospitais, asilos e assemelhados.

Num libreto popular que propõe apresentar os melhores pensamentos sobre as mulheres, encontra-se o seguinte:

"Ninguém se opõe a uma mulher que é uma boa escritora, escultora ou geneticista se ao mesmo tempo ela conseguir ser boa esposa, boa mãe, ter boa aparência, bom temperamento, enfeitar-se bem e ser pouco agressiva" (Leslie McIntyre apud Hexley, 1996).

Vê-se que cultura e a biologia se imbricam de forma a proporcionar reforço recíproco uma à outra, e a criar condições para que se possa falar de situações ligadas à saúde/doença que excedam ao pólo biológico dessa relação, tornando necessário que se procure no outro pólo a lógica de seu aparecimento. Tal é o caso dos nervos, que, embora não exclusivo do sexo feminino, parece nele predominar e, valendo-se das suas particularidades fisiológicas, apresentar uma exuberância de manifestações e de usos culturais não vista entre os homens nervosos.

Freud repôs (e advogou) tratamento catártico para a histeria e desordens nervosas relacionadas com o método psicanalítico. Significativamente, a vulnerabilidade feminina (baseada no útero) tem sido reposta com um equivalente psicológico. A teoria psicanalítica falocêntrica reivindica que desordens mentais e comportamentais femininas originam-se do desajustamento de seu papel feminino e sua fisiologia falha (carente). Embora algo renomeada, a forte associação entre mulheres e nervos continua (Cayleff, 1988b).

\section{Gênero e IniqüIdaders na Saúde}

Já se comprovou, no que diz respeito às mulheres, que gênero constitui uma variável preditiva de morbidade, junto com outras variáveis socioeconômicas com as quais está inter-relacionado, como índices de emprego e desemprego, estado civil renda etc. (e. g. Dohrenwend \& Dohrenwend, 1976; Haavio-Manilla, 1986; Krieger, 1990;Zadoroznyj \& Svarstad, 1990; Arber, 1991; Anson et al., 1993; McEwam, 1993; Walters, 1993).

Além disso, gênero tem motivado o atendimento diferenciado na assistência médica, seja pela especificidade de características médico-fisiológicas, seja pelos preconceitos e estereótipos médicos a ele ligados. Estudos como o de Zoccolillo \& Cloninger (1986) mostram que, entre mulheres que somatizam, há um número excessivo de internações hospitalares e intervenções cirúrgicas, por eles atribuído à deficiência de informação na educação médica, em especial nos livros-texto de medicina. Os dados desses autores, que revisam a literatura sobre o assunto desde 1951, mostram que mulheres somatizadoras são duas vezes mais operadas do que as clinicamente doentes, e três vezes mais do que as sadias! 
Existe ainda extenso rol de publicações que mostram que, além das iniqüidades decorrentes de condições socioeconômicas, como desemprego ou subemprego, baixo poder aquisitivo e outras, as mulheres sofrem, ainda, algumas paradoxais, como, por exemplo, receber com mais freqüência o rótulo de somatizadoras e, em contrapartida, quando se trata de prever a evolução do caso, ser-lhes dirigido maior número de prognósticos sombrios!

Já mencionei o fato de que em minha formação médica também fui treinada para considerar grave, por princípio, um caso masculino de uma pessoa aparentemente em coma, mas a pensar em piti, em primeiro lugar, se for uma mulher. Recentemente, uma nota em um jornal nacional de grande circulação, cuja chamada era "Enfartadas e confusas", informava que as mulheres demoram mais a chegar ao hospital quando apresentam sintomas de infarto e que lá não são atendidas com urgência, porque os médicos não reconhecem (nas mulheres!) tais sintomas de ataque no coração, pois estão acostumados a considerá-las somatizadoras e, como tal, não merecedoras de cuidados imediatos! (Jornal do Brasil, 1998).

O que se passa com o atendimento às nervosas nos serviços médicos é sintomático das outras iniqüidades ligadas a gênero; até mesmo a receita azul permite perceber o recorte de gênero e suas implicações práticas: "Aqui, de quatro receitas azuis, três são paras mulheres e só uma para homem. É... umas três receitas chegam por semana. Não que as mulheres sejam mais fracas ou os homens mais fortes..." (dono de farmácia no Campeche).

Destacando nervos na multiplicidade de afecções que podem atingir as mulheres, a pesquisa mostrou como elas próprias se sentem em relação à biomedicina e como esta as trata, ensejando que um olhar perscrutador e crítico estendesse a reflexão para outras situações. Assim, nervos serviu de mote para se pensar sobre as iniqüidades no atendimento à saúde derivadas das questões de gênero, tais como as já comentadas.

\section{Nervos como um Problema das Mulieres}

A sociedade em que vivemos está estruturada para o homem e pelo homem, motivo pelo qual a identidade da mulher é fragmentada pelas várias funções que desenvolve. A mulher não é reconhecida a não ser em sua função reprodutora. Reduzida a essa, sofre as repercussões dessa

limitação, e se escapa do mundo doméstico, sofre a esquizofrenia da inserção na produção, em oposição às tarefas de casa. Tudo isso repercute em sua saúde mental e ela fala através do seu corpo dos problemas que não pode expressar e que estão inscritos na ordem patriarcal. Entretanto, o reconhecimento desse problema não passa pela simples reivindicação de igualdade, e sim pelo respeito à diferença.

Conferência Nacional de Saúde e Direitos da Mulher, outubro de 1986, Relatório Final 
O nervoso não é um atributo feminino, tanto que em nosso país os autores que o têm abordado - como Duarte, Costa, Scheper-Hughes, Souza, Mombelli (1992b), entre outros - mostram tanto homens quanto mulheres atacados dos nervos. Porém, esses autores e outros, em pesquisas na Ilha de Santa Catarina que, embora não direcionadas ao nervoso, o observaram em proporções alarmantes (e. g. Elsen, 1984), também mostram que o problema apresenta maior incidência entre as mulheres. Cogitam a hipótese de que os homens disporiam de mais válvulas de escape socialmente sancionadas, como o álcool, a maior frequiência aos espaços públicos, o maior convívio com amigos e que, sobretudo, estariam expostos a menor sobrecarga de tarefas estressantes como, por exemplo, o cuidado dos filhos, que é atribuição feminina. São explicações e, ao que parece, diferenças atribuíveis à variável sexo, semelhantes às referidas por O’Nell \& Selby (1968b) para o susto em povoados zapatecos no México.

$\mathrm{Na}$ visão das próprias pacientes, o nervoso pode incidir indistintamente em homens ou mulheres, mas lhes parece que a exteriorização do sofrimento feminino é mais fácil, talvez socialmente mais legítima:

Eu conheço homens e mulheres que sofrem; só que nós, mulheres, contamos o que sentimos e não temos vergonha, e eles não, são mais fechados; mas quando ocorre a doença eles cedem, porque nervos é fogo, é uma crise terrível, aí não tem homem nem mulher, naquelas horas nos tornamos frágeis e com medo de tudo; o que queremos é ser ajudados de qualquer forma! (Texto de paciente)

Elas também entendem que para os homens estejam disponíveis, socialmente, mais válvulas de escape para as tensões cotidianas do que para as mulheres. O mesmo pensava o dono da farmácia local: "eu acho que os homens têm mais formas de espairecer, saem, vão para o bar, bebem um pouco, fumam, conversam, vão pescar, e as mulheres não têm isso".

Relacionar nervos e nervosismo com as mulheres é coisa corriqueira, meio anedótica até. $\mathrm{O}$ vulgo o faz diuturnamente, sem nem pensar mais nas razões que o levaram a assim proceder. No entanto, o nervoso, mesmo não sendo seu predicado exclusivo, se abate sobre elas com frequiência, e são as mulheres que, em nosso meio, costumam deixá-lo manifestar-se nas suas formas menos dissimuladas, mais abertas e exuberantes:

Meu tio mesmo sofre dos nervos, só que acham que para um homem dizer que sofre dos nervos fica muito feio, então na frente dos outros ele se controla, só estoura com a mulher e os filhos. Já uma mulher, não, não se segura (...). Se precisa gritar, grita, se bate, não consegue ficar quieta; se está estourando por dentro, estoura para fora também. (Paciente)

Sei de uns [homens] que sofrem dos nervos, vivem tomando remédio controlado, mas a gente nunca viu eles fazerem barulho que nem uma mulher que seja nervosa. Já vi umas serem levadas no posto de saude arrancando as roupas, berrando que nem animal, gritando o tempo todo, sem ninguém entender nada. Só acalmam com uma injeção de calmante, aí se aquietam um pouco! (Informante) 
Acho que é da natureza das mulheres terem o nervo assim, parece que não podemos segurar. Os homens parece que podem sofrer mais calados. (Paciente)

Mas havia quem percebesse a ação da cultura implícita na possibilidade, ou na impossibilidade, de alguém se expressar por meio de uma crise de nervos:

Ah, claro que eles também têm problemas, só que se um homem se agitar assim que nem uma mulher nervosa, passa muita vergonha, né? (Informante)

Ora, se um homem se atacar assim [como uma mulher] dos nervos, vai parar na Colônia. (Informante masculino) ${ }^{1}$

É próprio dos homens serem assim, mais agitados, mas isso não quer dizer que sofram como a gente, é o jeito deles mesmo, se um homem não é assim, aí é que é estranho. (Paciente)

Razões para predispô-las à suscetibilidade ao nervoso estão presentes em toda a literatura que trata de mulheres e dos seus papéis. Inicialmente, buscava-se na biologia aval para posições a respeito da mulher. Esse aval lhes conferia, em geral, condições de desigualdade (com implicação de inferioridade) perante os homens, decorrentes de sua diferença biológica. As posições mais atuais procuram desnaturalizar a questão, deslocando o eixo da biologia para a cultura, espaço no qual é construído o conceito de gênero que adotei neste trabalho.

Reconhecendo que masculinidade e feminilidade não são atinentes ao sexo, mas ditadas pela cultura, ao falar de gênero refiro-me também às construções simbólicas do feminino e do masculino, das articulações de poder, da dominação tradicional das mulheres pelos homens e do espaço de poder feminino no interior de cada cultura (Grossi \& Miguel, 1990).

Em O Autoritarismo e a Mulher: o jogo da dominação macho-fêmea no Brasil, d'Ávila Neto (1978) localizou as origens dessa dominação na permanência de traços da sociedade patriarcal, mesmo no meio urbano atual, da qual derivaram também os preconceitos, os tabus e os complexos (eu preferiria conceitos) de virilidade e virgindade. $\mathrm{O}$ autor analisa ainda a forma como a evolução dos papéis funda-se em estereotipias, como a ligada ao mundo do trabalho: há carreiras masculinas e carreiras femininas.

Há referências na literatura médica e antropológica à correlação entre fatos ou períodos da vida fisiológica da mulher, tais como os ligados à reprodução (menarca, ciclos menstruais, gravidez, puerpério etc.), e as perturbações, sendo que uma das mais comumente apontadas é o nervoso.

Quando eu fiquei moça eu estava trabalhando, aí vinha aquela borra... parou a menstruação. Eu não falei nada para a patroa, eu não era de contar mesmo. Aí passei o dia inteiro co'aquela dor. (Paciente)

Nas gravidez, desde o primeiro dia eu sabia que estava grávida, tudo se acabava para mim, desde a primeira foi assim (...) às vezes a menstruação continuava a vir, noutras dava outros sintomas, mas sempre eu tinha problema e os nervo incomodando. (Paciente) 
Até hoje-eu acho que todo esse meu problema foi por causa de abortar uma filha, que até hoje eu não me esqueço, eu tenho a consciência pesada por causa disso (...) Comecei com isso [com as crises de nervos] acho que porque fiquei com aquilo [o aborto] na minha cabeça. (Paciente)

Este trabalho não comportaria um levantamento extenso de toda a vasta bibliografia, de fundo conceitual, que se acumulou em torno da discussão sobre gênero no Brasil e suas implicações sobre o papel feminino. Apontei, modestamente, apenas as questões mais básicas, relacionadas ao problema do nervoso.

\section{O Nervo Cala, o Nervo Fala: o nervoso como linguagem social}

Fico com nervo, que não consigo falar, o que até é bom, porque às vezes quando está nervoso a gente fala o que não deve, dá arrependimento depois.

(Paciente)

O nervoso, por ser socialmente reconhecido, e, portanto, abordado dentro de padrões terapêuticos e de comportamento próprios, corresponderia ao que Verani \& Morgado (1991a) chamam de síndrome cultural: um fenômeno com implicações de várias ordens, inclusive a biológica, que a cultura local define com mais precisão do que a medicina ou a epidemiologia, por localizar a relação entre indivíduo e sociedade no contexto da articulação da cultura com a biologia.

Constituindo uma linguagem e um discurso socialmente compreensíveis e aceitos, tal fenômeno permite que os circunstantes saibam o que o doente está expressando por meio dele e ajam de acordo com esse significado. Condensa uma experiência pessoal na vida social, funcionando como um idioma social reconhecido e permitindo ao doente o acesso a uma situação de privilégio: atenção especial, alívio de certas obrigações, proteção, divisão não usual de tarefas etc.

Como representação social, o nervoso é um fato coletivo, ou seja, tem um significado que tanto atinge quanto é compreendido por qualquer pessoa a qualquer tempo.

Como idioma, o nervoso pode demonstrar experiências semanticamente expressas e redes de interação social, permitindo ainda que se destaquem da vida social alguns papéis que dele se utilizam com freqüência, como os femininos. Tem usos e finalidades. Pode demonstrar opressão da ou na vida diária, problemas da sexualidade, dificuldades de relacionamento social etc. Por isso, o interesse em relacionar suas causas aos seus significados, considerando-se que a doença não é um acontecimento meramente biológico, mas um acontecimento que expressa uma conjuntura pessoal, social ou política adversa:

Sou o homem e a mulher da casa, dobra tudo pra a gente que é sozinha. (Paciente)

O poblema dos nervo é horrivel porque é uma falta de amor, de carinho, sei lá... (Paciente) 
Teve um tempo que ele bebia, me incomodava demais, eu chorava muito, meu consolo era chorar. (Paciente)

A síndrome pode representar um meio de expressão de insatisfação ou de funcionamento social inadequado:

Eu não podia ver nada velho dentro da minha casa que me dava vontade de meter os pé, eu chegava... Até o dia que eu quebrei duas cadeira e uma mesa e então o meu marido comprou tudo novo. (Paciente)

Se a gente está mal, quer mesmo é que todo mundo saiba, parece que a gente tem que dizer de algum jeito que as coisas não vão bem. Aí se a gente não consegue falar, no começo da crise parece que eu fico muda, ou eles não prestam atenção, dá aquela vontade de gritar, de sair que nem louca, berrando. Parece que nunca mais a gente vai ter controle sobre aquilo... só quer berrar mesmo! (Paciente)

Às vezes eu quero guardar uma coisa, assim um fato só para mim, por exemplo uma má palavra de alguém. Mas aí, o nervo me ataca, eu fico sem poder falar, mas mesmo que fique muda, todo mundo sabe, é como se eu ficasse dizendo pra todos o que tá se passando. (Paciente)

Aqueles casos em que há lesão orgânica, como a hipertensão arterial, as úlceras pépticas e outros mostram que a patologia serviu de significante ao qual foi atribuído significado social e cultural pelos nativos. Casos assim reforçam, social e culturalmente, a síndrome (Verani \& Morgado, 1991b), por darem uma expressão corporalizada, culturalmente informada de conjunturas pessoais, sociais ou cosmológicas adversas.

Ele [o médico] me examinou, mandou tirar radiografia, aí na radiografia deu a coluna desviada, deu bico-de-papagaio, deu não sei o que mais, que já estava com coisas incuráveis (Paciente)

E, em outra ocasião:

Elas mediram a minha pressão, que estava bem alterada, estava alta, né? Também, do jeito que eu estava, como estavam os meus nervos, né? (Paciente)

\section{Nervos como Cena num Drama Relacional}

Levar a representação às últimas conseqüências. O que fazemos todos os dias (representar) mal e porcamente, o que nos humaniza, assim cheios de pontas irresolvidas que somos... (grifo meu)

Cristóvão Tezza

Na sua multiplicidade de apresentações, usos e finalidades, pude compreender os casos de nervos entre as mulheres do Campeche como atos ou cenas representativas de crises dentro dos dramas sociais que se desenvolvem à custa de situações relacionais, as quais demandam formas coletivas de resolver ou de reequilibrar o grupo social envolvido. 
A cena dos nervos, nesse caso, faria parte de um jogo relacional, ligado principalmente a relações conjugais. Como parte do drama, levava ao ápice dramático quando esse jogo deixava de ser suficiente para manter mais ou menos equilibrados os participantes. Poderia, nesse caso, ser entendida como um equivalente da cena barthesiana: “A cena é, pois, interminável, como a linguagem: ela é a própria linguagem, apreendida no seu infinito, essa adoração perpétua que faz com que, desde que o homem existe, isso não pare de falar" (Barthes, 1991:38) (grifos do autor). Ou da cena descrita por Gregori em Cenas e Queixas (Gregori, 1989), que, além de preparar a guerra, abriria espaço para que a vítima emitisse seu pedido de socorro e que a relação se reequilibrasse.

O sofrimento de nervos, por vezes, atuaria assim, em suas inúmeras recorrências, como uma espécie de estribilho dramático, um solo denunciador, secundado por muitas vozes que se rendem às suas ordenações enviesadas:

Eles não tavam nem ligando para o que eu dizia... Mas dai, quando comecei a gritar que nem uma louca e a me bater, que eu não conseguia me segurar mais, eles tiveram que me acudir, señ̃o eu ia cair da escada, então eu disse: é só assim que vocês me escutam? Quando eu peço para me ajudarem a pendurar a roupa, que eu não posso tomar sol que me dá a tontura, vocês fazem de conta que não escutam ou não acreditam, então é preciso eu cair para virem me acudir? (Paciente)

Parece que só me ouvem quando eu estou ruim mesmo, se pego gritar e me bater, aí sim, correm me ajudar, saber o que eu quero. Por que não vêm antes, quando eu peço? (Paciente)

Os filhos dela andam por aí, nem ligam para a mãe, só ficam por casa e ajudam quando dá as crises nela. (Informante)

Narrando suas dores e mal-estares, as pacientes mostram que sua vida é um caleidoscópio de sintomas cujos significados giram com eles e se recombinam na mesma medida, gerando a cada episódio uma nova interpretação ou uma nova necessidade. Nesse ponto, na representação do drama da existência concreta da vida de cada uma, é que parece situar-se a grande diferença entre nervos e o diagnóstico médico que o reduz à histeria e trata-o com toda a carga dos preconceitos historicamente acumulados.

Nervos insiste em exibir, em tornar públicos os dramas da vida privada, buscando reanimar, refazer os liames de uma rede social que em certos momentos se afrouxa.

Nervos medicalizado simplesmente, domesticado pelas drogas (em que pesem ser medicamentosas), perde essa visibilidade social, tirando de cena não só um dos atores mais destacados, mas o próprio drama social. 


\section{Nervos E VIOLÊNCIA}

Ora, se utilizamos o conceito de gênero como categoria analítica das relações homem/mulher, é evidente que masculino e feminino são construções simbólicas e históricas que inexistem separadamente. Portanto, o imaginário e o uso da violência nas relações de gênero implica, sim, uma relação concreta entre cada mulher $e$ cada homem em cada relação conjugal/emocional determinada, relação da qual as mulheres são participantes ativas e não passivas do desejo alheio. O lugar de passividade pode fazer parte do jogo relacional, mas não necessariamente remeter a uma visão estática de um feminino a-histórico e a-cultural. (grifos meus)

Grossi

A protagonista do drama dos nervos, pela manipulação que exerce sobre os outros atores, ou pelo menos sobre um deles, aquele com quem o seu relacionamento está mais comprometido (no sentido duplo de ser aquele cuja atenção a interessa mais e, ao mesmo tempo, aquele que mais a afeta, mais lhe causa mal-estar), age com violência, se a tomarmos pela definição de Chauí:

Em primeiro lugar, como conversão de uma diferença e de uma assimetria numa relação hierárquica de desigualdade, com fins de dominação, de exploração e de opressão. Isto é, a conversão de diferentes em desiguais e a desigualdade em relação entre superior e inferior. Em segundo lugar, como a ação que trata o ser humano não como sujeito mas como uma coisa. Este se caracteriza pela inércia, pela passividade e pelo silêncio, de modo que, quando a atividade e a fala de outrem são impedidas ou anuladas, há violência. (Chauí, 1985:35)

Assim, a crise pessoal e/ou social, representada pela cena dos nervos, teria um potencial coercitivo, subliminar talvez, distinto de outras formas de exercer violência (como as físicas, por exemplo). Mas pode igualmente manipular os circunstantes, fazendo com que ajam contra a vontade, só para amenizar a crise e permitir seu refluxo:

Não quero que ninguém fale comigo [na crise] e eles [marido e filhas] ficam no desespero, não sabem o que fazer. Ele pergunta: o que você quer que eu faça? Diga o que você quer, eu faço o que você quiser. (Paciente)

Vocês não me escutaram não? (...) Agora, daqui para frente, eu não vou gritar mais (...), então vou deixar quebrar, de algum jeito, ou da pancada ou de bater em algum lugar, vou deixar quebrar minha cabeça... para eles sofrer! Tem que sofrer, eu vou sofrer, mas quem vai sofrer também são eles, porque não tão nem aí... mas pelo menos eu vou ter que ficar mais tempo na cama e não sei como eles vão poder sem mim, como vão se arranjar... (Paciente) 
Meu marido e meus filhos, pra não me dar uma crise, fazem coisas que não fariam nem por muito dinheiro... coisas que outros homens não são capazes de fazer, nem pra ajudar a própria mãe. (Paciente)

O marido infiel ou desinteressado da esposa, que conta com o aval dos padrões locais para ter casos com outras mulheres ou para demorar-se nos bares e pontos de encontro dos homens, pode ser arrastado de volta para casa para atender uma mulher doente:

Aíme deu dez crises dessas, todas as dez deram às seis da tarde [pouco antes da chegada do marido, que por essa época estava com uma nova amante e costumava visitá-la nesse horário; com a repetição das crises da esposa, ele deixou de fazer isso, vindo para casa tão logo deixava seu labor]. Aí eles me mandaram para o hospital S. José, o médico não me deu calmante (...), me levaram numa benzedeira. Ela falou que a minha doença era esgotamento nervoso. Aí ele não teve outro recurso, teve que largar dela e vir me cuidar, que todo mundo [vizinhança e parentes] pegou no pé dele, que eu estava doente por causa do que ele me fazia. (Paciente)

Ele [o marido] não quer me ajudar em casa, diz que é feio um homem fazer serviço de mulher, só mesmo se me der a crise, aí ele faz tudo, até limpar bunda de nenê se precisar, faz comida, lava roupa. Ele diz que eu tenho os ataques só porque não agüiento os serviço de casa e os filhos. Mas é assim mesmo, só eu ficando atacada é que ele me ajuda. (Paciente)

Tanto o marido como os filhos, que já são rapazinhos, só querem saber de ir num bar, de ver televisão e sair com a turma deles por aí, pela praia, futebol, cinema... nada de ajudar. Só se ela tiver uma crise, á sim eles fazem tudo para ela. Às vezes chego a pensar que inventa a doença para eles ajudarem, mas quando vejo com crise, tadinha!, fico arrependida de pensar assim, coitada, ela sofre demais! (Informante)

Aí eu disse pro meu marido bem assim: você vê, eu estou aí sofrendo dos nervo, tudo por tua causa, tu fica lá com aquela dona e eu aqui sofrendo com os filhos! Tu tem que decidir: ou eu ou ela! Daí ele escolheu eu, e voltou para casa. (Paciente)

$\mathrm{Na}$ e pela crise, manipula-se também o pessoal dos serviços de saúde para se obter atendimento imediato e, principalmente, novas receitas azuis:

Ela, uma vez, tomou uma caixa inteira de calmante lá no INPS só porque o médico disse que ela ainda tinha e que ele não ia dar outra receita. Aí ela disse: ah, então vocês vão ver! Pediu uma água, agarrou tudo e pôs na boca, de uma vez só. Engoliu tudo na frente deles, ela quase quebrou tudo por lá, aí o doutor teve que dar outra receita para ela. (Informante)

Quando vou ficando com pouco remédio, que eu não tenho mais receita azul, vou no posto; se eles não querem me dar mais, já vou me atacando, aí uma delas [das funcionárias] vai lá e fala pros médicos que já me conhece e sabe como eu fico quando me dá o nervo, então o doutor faz a receita e manda entregar o remédio. (Paciente) 
Uma vez a doutora que estava ai no posto do Campeche disse que chegava de dar remédio azul para mim, que eu parasse. Aí foi me dando um desespero, eu garrei a pensar como faria se voltasse a dar as crise, o que que ia me socorrer, e desandei a chorar, ai ela viu que eu não podia mesmo ficar sem ele e me deu receita para dois meses. (Paciente)

Ela ia ser a última a ser atendida, dizia que tava mal e ninguém [entre os funcionários do serviço de saúde] ligava, então ameaçou tirar a roupa e saiu correndo para a praia, dizendo que ia se atirar no mar! Enião correu todo mundo, até quem tava para ser atendido no posto, e agarraram ela e aí a doutora atendeu primeiro, foi o único jeito dela sossegar: (Informante)

A imprevisibilidade da crise cria condições de manipulação, principalmente do grupo familiar, uma vez que se as pacientes sofrerem incômodos, passarem preocupação, podem vir a ter uma. Assim, cobram constantemente do marido, dos filhos e dos pais atenção a seus pedidos e ao seu sofrimento:

Ó, manda as meninas buscar a roupa que eu vou deitar para não cair, senão eu vou cair, porque a minha cabeça estava rodando. (Paciente)

Aí quando eu tive crise de nervos eu vim pra casa da minha irmã [saindo da casa de um irmão e da cunhada que a maltratavam], que estava mais bem de vida, ela foi me buscar, me levou no médico, até hoje ela cuida de mim, é carinhosa comigo, faz tudo pra que eu não me incomode! (Paciente)

Hoje [depois que ela começou a sofrer dos nervos e ele abandonou a bebida e as amantes] vivo muito bem com meu marido, ele me paparica muito, também tem o maior medo que uma hora dessa me volte tudo, que pode voltar a qualquer hora, né? (Paciente)

Quando ela tem as crises dela, o pai, que é nervoso também, prefere fazer tudo que ela exige para não se incomodar. Então parece que ela se aproveita da doença, numa dessa já fez o pai dar uma casa só para ela que está alugada, agora quer que ele faça outra para ela morar sozinha, ele disse que não, mas eu tenho certeza que é só ela ter um ataque que ele vai dar o jeito de construir como ela quer! (Mãe de uma paciente)

Os filhos só acodem quando a gente está mesmo muito mal, senão dizem que não têm tempo, mas quando me dá a crise vêm correndo. (Paciente)

Paradoxalmente, por meio das crises e suas manipulações, conscientes ou não, parece que as pacientes ajudam a manter certos agregados sociais à sua volta, garantindo a manutenção de práticas tradicionais, como a dos mais novos prestarem ajuda aos de mais idade. Ao mesmo tempo, subvertem, em certa medida, a ordem ditada pelos valores locais, como no caso da transferência da responsabilidade pelo trabalho doméstico para os homens. 
NoTA

1 Destaquei aqui o sexo do informante, porque foram raríssimas as informações prestadas pelos homens; quando inquiridos sobre o tema, estes remetiam-se às suas mulheres ou mães. 